head more deeply sinuate at base. The plate will give an idea of the more salient features, the figures being drawn by Mr. P. C. Myers and the author. Fig. I is an outline of the type specimen, $a$ is the mandible, $b$ the maxilla, $c$ the labium (in which the palpus is shown on one side only, the paraglossa on the other), $\mathrm{d}$ the antenna and e the hind tarsus. Figs. $2 \mathrm{a}, 2 \mathrm{~b}$, and $2 \mathrm{~d}$ represent hitherto unfigured details of Platymedon laticolle which are of interest in this connection. It will be noticed that the terminal antennal joint is sinuate or somewhat ogival at tip. The mandibles are stouter than in Stilicus hanhami. The fourth joint of the maxillary palpi is extremely minute and scarcely visible except by careful preparation. The four teeth of the labrum (fig. $2 f$ ) are unequal, the outer being much smaller than the inner.

A nest of Lasius niger was examined at Iowa City on May 5 th. The gallerie were in and under old logs. Running with the ants were seen two individuals of Myrmobiota crassicornis Casey. They are difficult of detection owing to their habit of keeping close to their hosts and mingling with the moving mass. My other specimens of this beetle were taken in August so that this record points to the probability of hibernation or of a double brood.

During a six weeks' trip to Colorado, some effort was made to add to the records of myrmecophiles, but the season was so far advanced that but little success was achieved. At Colorado Springs two species were taken, which, with their hosts, have been identified by Prof. Jerome Schmitt. These were Batrisus frontalis which was found in the runways of Lasius claviger beneath a log; and Batrisus globosus which occurred in a colony of Camponotus herculeanus.

\title{
A STUDY OF THE CATERPILLARS OF NORTH AMERICAN SWALLOWTAIL BUTTERFLIES. - II.
}

\section{BY SAMUEL H. SCUDDER, CAMBRIDGE, MASS.}

From these statements we see that there is a somewhat general uniformity of type in the earliest stage of larval life among the Papilionini, while there is an extraordinary diversity in the same caterpillars when full grown. Some of them alter very much less than others, some assume the mature aspect by slow degrees, and others at a start and at very different periods of life.
Thus maturity may be said to be assumed at the second stage by Laertias and Iphiclides, at the fourth by Heraclides and Papilio, in the course of the fourth stage by Jasoniades, and not until the final stage by Euphoeades. This assumption of maturity consists in several distinct features which in general are correllated: the form of the body, the broad features of the coloring 
of the body and the loss of the juvenile armature. In only one instance, Papilio, are the tubercles of the larva retained (and here only for a single stage) after the adult form and markings have appeared; and, excepting Laertias where the markings are almost null through life, Heraclides is the only example where the ornamentation of the body of the adult in any way resembles that of the newly born caterpillar.

There are several distinct lines along which changes have occurred, permitting readier comparison between allied types and to set this forth more clearly the facts are here tabulated, the numerals representing the stages.

From this it would appear to be tolerably clear that the primaeval caterpillar of the Papilionini was covered with rows of fleshy, mammiform tubercles beset with bristles, and that these were retained through life; but that in the gradual development of the group these were lost, first at the final stage as we now find it in Papilio, afterwards at successively earlier and earlier stages ; the loss consisting, first, in the removal of the bristles, afterwards in the lowering of the tubercles until only smooth and shining lenticles remained, as now in the full grown caterpillar of Heraclides; these again, as in several genera, were replaced by colored spots, some of which in caterpillars so far developed as Euphoeades and Jasoniades, assumed special forms.

So when we come to the general color, it may be fairly presumed that the early caterpillar was of a dark color - in no way green as Weismann, from his study of the Sphingidae, seems to think all young caterpillars were; probably of a uniform dark color with a tendency toward a deepening of the tint of the region about the third thoracic segment (which early assumes a special importance in these caterpil-

\begin{tabular}{|c|c|c|c|c|c|c|}
\hline & $\begin{array}{c}\text { Laer- } \\
\text { tias. }\end{array}$ & $\begin{array}{l}\text { Iphi- } \\
\text { clides. }\end{array}$ & $\begin{array}{l}\text { Jason- } \\
\text { iades. }\end{array}$ & $\begin{array}{l}\text { Euphoe- } \\
\text { ades. }\end{array}$ & $\begin{array}{l}\text { Hera- } \\
\text { clides. }\end{array}$ & Papilio. \\
\hline 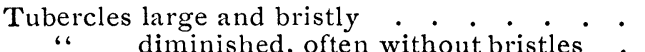 & I & I & I & $\begin{array}{c}1 \\
2-3\end{array}$ & $2-2$ & $\mathrm{I}-3$ \\
\hline $\begin{array}{l}\text { diminished, often without bristles } \\
\text { changed to lenticles . . . . }\end{array}$ & & & $\begin{array}{l}2 \\
3\end{array}$ & $2-3$ & $2-3$ & 4 \\
\hline Lenticles changed to spots $\ldots,: \quad$. & $2-5$ & & $\begin{array}{l}3 \\
4\end{array}$ & $\begin{array}{l}4 \\
5\end{array}$ & $4-5$ & $\begin{array}{l}4 \\
5\end{array}$ \\
\hline No conspicuous tubercles . & $2-5$ & $2-5$ & $3-5$ & 4-5 & $4-5$ & $\begin{array}{l}5 \\
5\end{array}$ \\
\hline Filaments $\cdot \therefore \cdot \cdot \cdot \therefore \cdot \cdot \cdot \cdot \cdot \cdot$ & $2-5$ & 0 & 0 & 0 & 0 & $\mathrm{o}$ \\
\hline Body pretty uniformly cylindrical & $I-3$ & $\mathrm{I}$ & I & I & $\mathbf{I}$ & \\
\hline " slightly tumid in front $. \quad . \quad . \quad . \quad . \quad$. & & & 2 & & $2-3$ & I -3 \\
\hline “ distinctly & & 2-5 & $3-5$ & $2-5$ & $4-5$ & \\
\hline 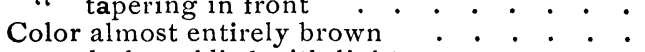 & $\begin{array}{l}4-5 \\
1-5\end{array}$ & I & & & & $4^{-5}$ \\
\hline “ dark, saddled with light $\dot{A}^{\prime}$ iransversely striped with black and bright & & $2-5$ & $I-4 \frac{1}{2}$ & I -4 & $\mathrm{I}-5$ & $\begin{array}{l}\mathrm{I}-3 \\
4-5\end{array}$ \\
\hline Curving lateral stripe in front..$^{\circ} \cdot$. & o & o & o & $2-4$ & $4-5$ & $\mathrm{o}$ \\
\hline Bright spots in rows on abdominal segments & $2-5$ & o & 2-5 & $2-5$ & 0 & $2-5$ \\
\hline A thoracic ocellus & o & o & $<2$ & $<2-5$ & o & o \\
\hline Special markings on first abdominal segment & o & $\mathrm{o}$ & $4 \frac{1}{2}-5$ & 5 & 0 & 0 \\
\hline
\end{tabular}


lars), and also about the seventh abdominal segment, by the tendency of both markings and dermal appendages to assume a polar arrangement in elongated forms. By this means arose through the intensification of these contrasts the lightening of the middle parts of the body to form a saddleshaped, whitish patch - a marking surely of great antiquity in swallowtail caterpillars, since it is now found at birth in four of our six genera, and a fifth shows a tendency toward it. This style of marking has been retained throughout life in Heraclides only of all the members of our fauna; and as it it is in just this genus alone that the lenticle-traces of the tubercles persist to maturity, we have certainly in Heraclides the perpetuation of a very antiquated type.

That in Papilio we have also a very persistent type may be judged from the great stability of the upper tubercles, which are even not lost until after the assumption of the changed livery of maturity, - a livery which owes a part of its variety and enlivenment to exchange of some of these tubercles for bright colored spots; these break up the transverse black stripes in a variable degree, and the stripes themselves appear to be but little more than retention of parts of the original color (fixed at the particular spots they occupy by the central position of the black tubercles) when the green livery of adult life is assumed. For it seems to be a green resembling the green of the leaves upon which the caterpillar lives, that is the ultimate aim of most Papili- onid coloration. In caterpillars of their size other colors would be too conspicuous for their advantage, and variation in this direction would be natural. Moreover, it is the color reached or partly reached, in several different ways, as the development of the other types show; thus in the other striped caterpillar, Iphiclides, the stripes grow obsolescent toward maturity and leave the caterpillar more completely green.

We may then trace several lines, to a certain extent parallel, along which the modification of the caterpillars of Papilionini has developed, parallel at least in that the loss of the juvenile bristles has been universal but at different stages; also that the loss of the juvenile tubercles has been universal though not always complete, their loss being generally made good by lenticles and these by spots; and sometimes, by acceleration, a phyletic stage is set further and further back and finally, perhaps, crowded out.

One of these lines, very distinct from the others, is found in Laertias, which has developed to so high a degree that its juvenile bristles, themselves exceptionally simple, are completely lost with the earliest stage; so, too, most of the tubercles; but here a very curious change occurs: those which are lost are replaced in new positions by others entirely different, which take on a more elongated form and become more properly fleshy filaments; while those which remain assume also the new development. The dark and almost uniform color of the larva throughout life is to be explained probably by acceleration; 
it is the mature color thrust back into the juvenile stage, to the obliteration of any trace of the saddle which once may have prevailed there; and is in keeping with the present almost complete assumption of the mature characters at the second larval stage. In support of this position I would point out that traces of the saddle still exist in the mature forms of other filamentous caterpillars of Papilionini allied to Laertias, - Ornithoptera, Menelaides, etc., indicating a still larger development of the same in the earlier stages of the types with which, unfortunately, we are not yet acquainted. In Laertias, then, the saddle has been crowded back out of existence.

Another line of nearly as high development we find in Iphiclides, where the extraordinary bristles and tubercles are lost with the very first stage and maturity marks the second. Here again no saddle appears, the only trace of it left being in the slight deepening of the color in the new-born caterpillar near the extremities of the body; here I conceive that the phyletic stage marked by the saddle and formerly developed in later stages from the incipient contrasts of the first, has been pushed back without invading the first until it is entirely skipped.

A third line is represented by the remaining genera in which the saddle is definitely formed and becomes a marked feature of the earliest stages, to be lost only at a comparatively late period of life, - in one instance, Heraclides, not at all. Its loss, however, is effected in two very different methods, as already pointed out, in Papilio and in the other genera, indicating lines along which future strikingly different processes may go on with widely different results; - in curious contrast to the somewhat similar results following quite different lines which we see in Iphiclides and Papilio. In Euphoeades and Jasoniades we see also the development of special and complicated markings from the simple spots which have replaced the tubercles; traces of the same may be seen in Heraclides.

This review has but imperfectly shown what curious and striking distinctions in form and coloring are possible, distinctions which indicate within the history of single lives the immense phyletic changes that have occurred within the group. These changes are far greater both in structure and in design than can be proved to have occurred in other phyletic types among butterflies, to which have been universally accorded by the most conservative of systematists the rank of genera. Shall we refuse to recognize and so consign to oblivion the more interesting, more important and more obvious differences which here obtain by classing all the forms under one, wide-reaching generic name? It were a veritable travesty of Nature.

\section{Explanation of Plate 5.}

Fig. I. Laertias philenor.

2. Iphiclides ajax.

3. Jasoniades glaucus (After Gruber).

4. Euphoeades troilus.

5. Heraclides cresphontes.

6. Papilio astyanax. 

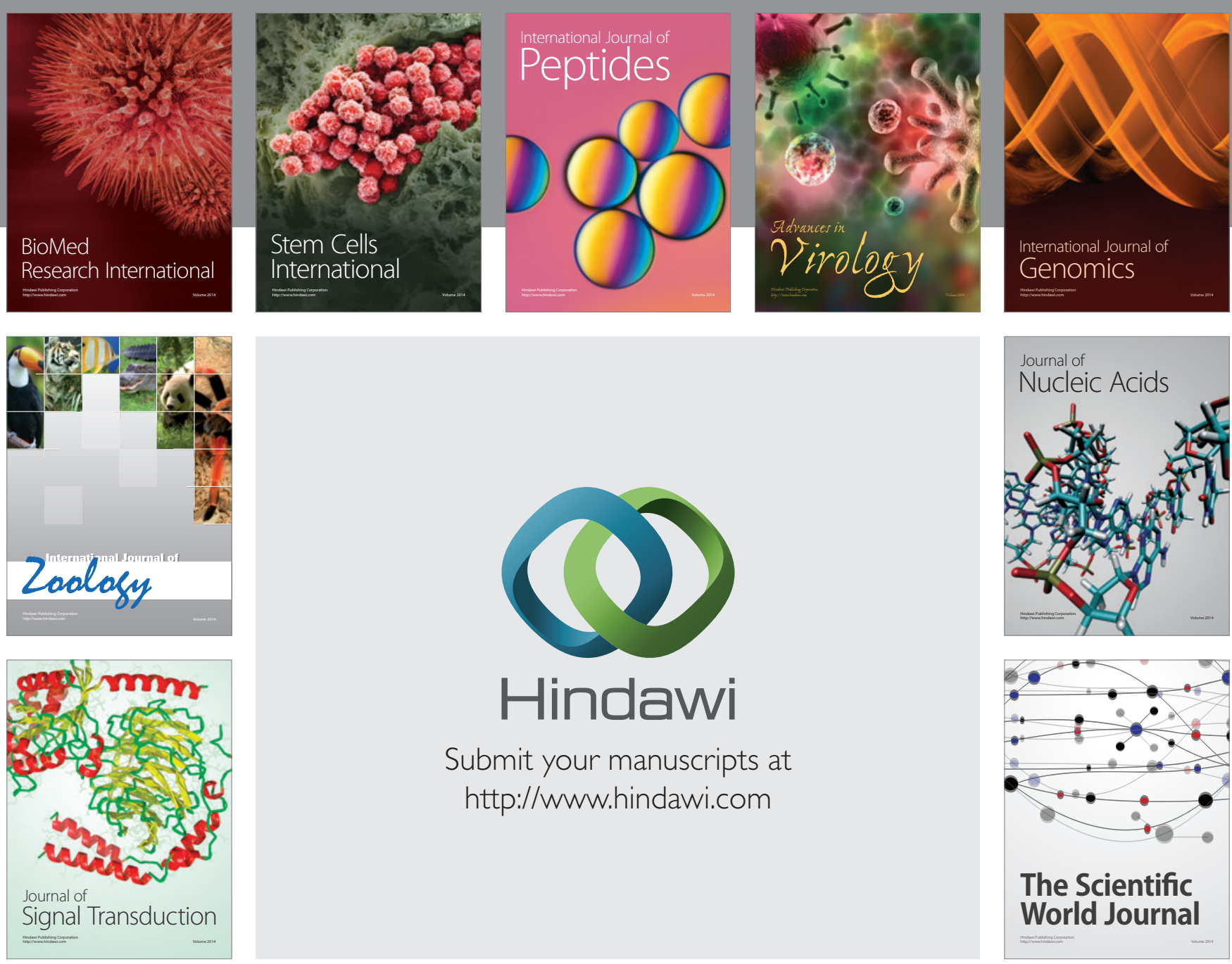

Submit your manuscripts at

http://www.hindawi.com
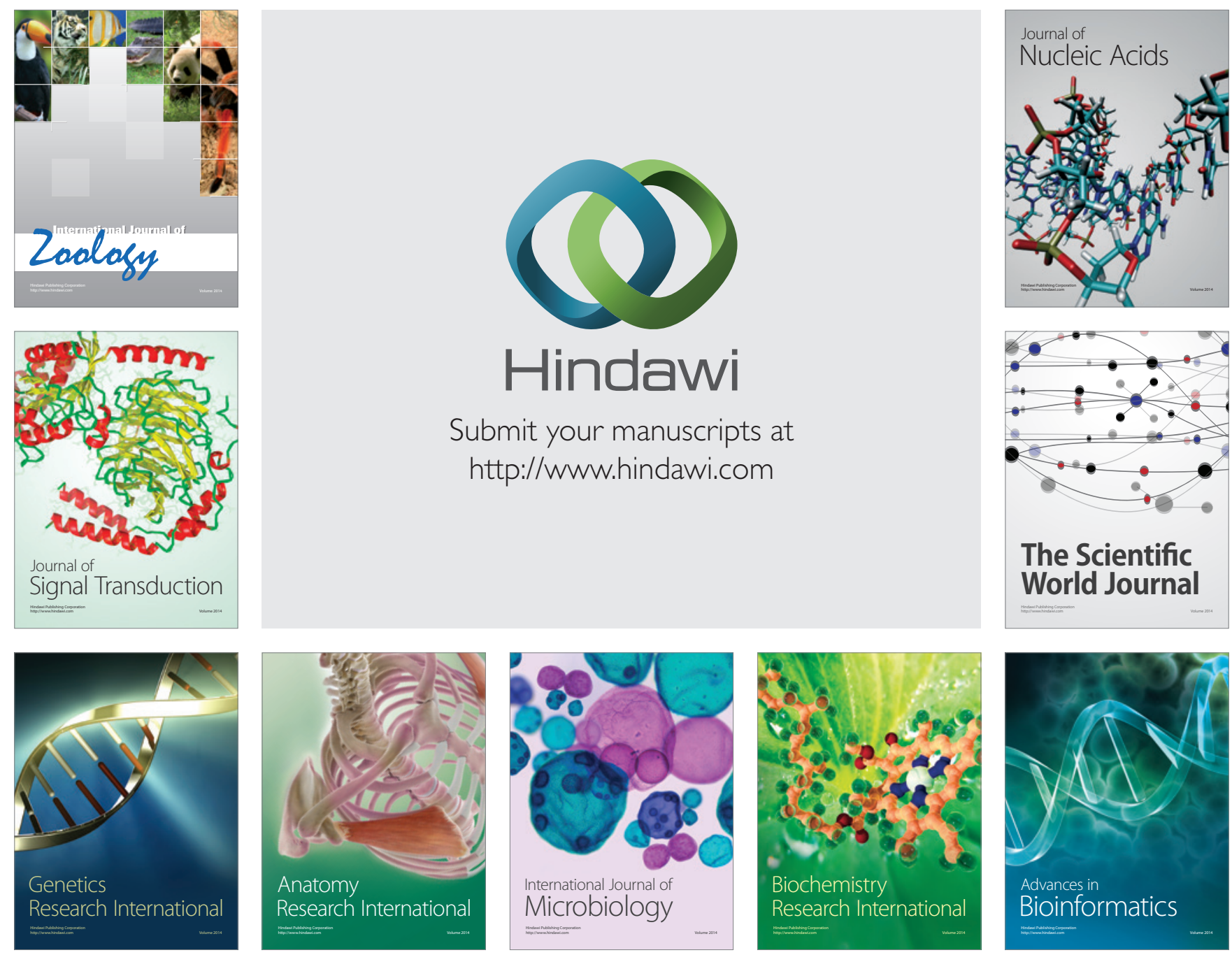

The Scientific World Journal
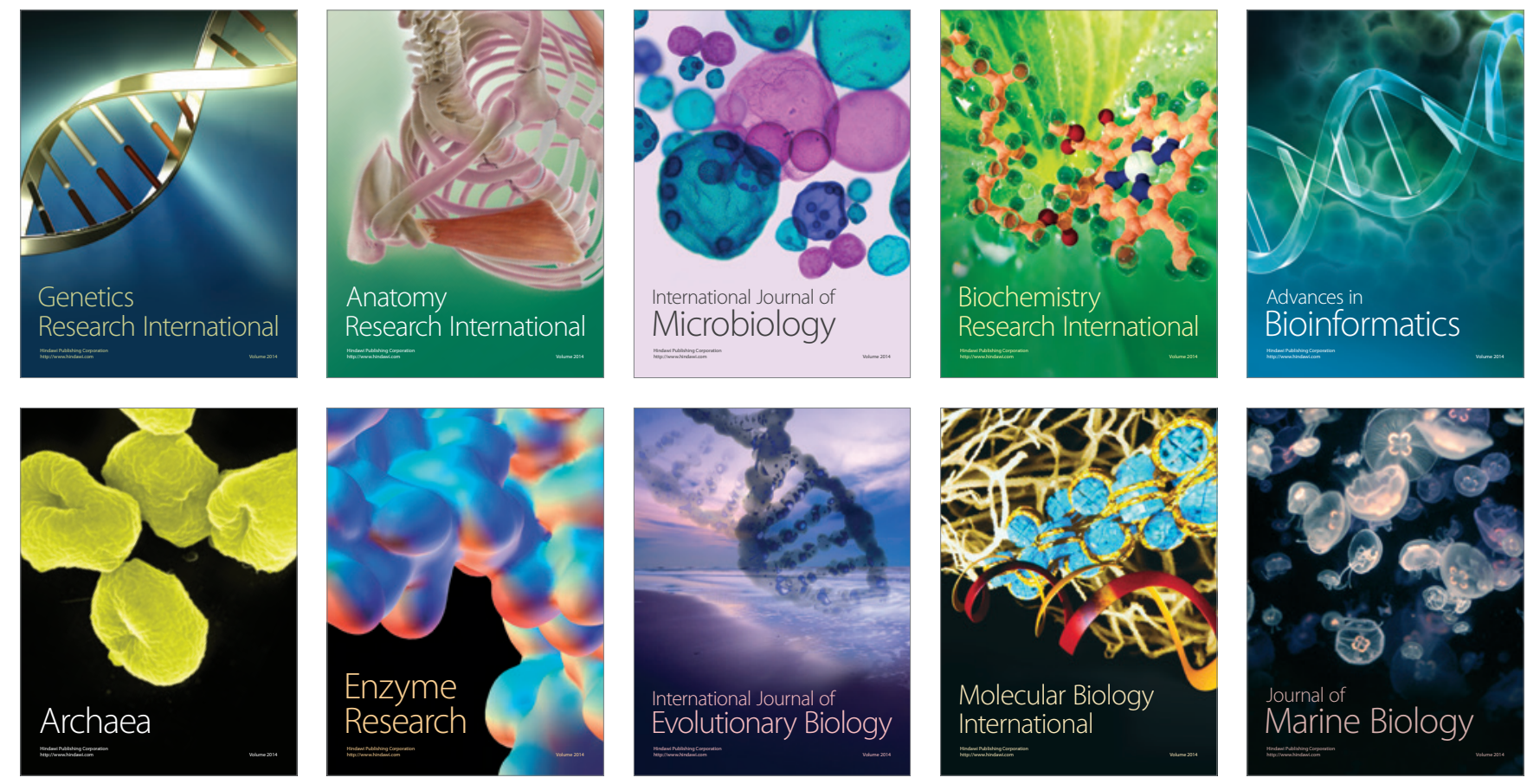